\title{
Hatching a new plot in reproductive genetics: from mutations to mosaics
}

\author{
David F. Albertini ${ }^{1}$ \\ Published online: 15 August 2019 \\ (C) Springer Science+Business Media, LLC, part of Springer Nature 2019
}

\begin{abstract}
"Mutations are the result of the flexible, versatile, but inherently uncertain system through which genetic information is converted into the working parts of an organism during embryogenesis or is passed on to the organism's offspring during gametogenesis." Irving Rothchild, 2003 [1]
\end{abstract}

Professor Rothchild, a pre-eminent reproductive biologist who dared to take the problem of our fecundity into the morass of evolutionary thought circles, saw the pieces of the puzzle aligning two decades ago when he issued the above statement. Taken at face value, his words impart motion to the process of inheritance via embryonic development on the one hand and through the generational course enacted through the germline. Gametes and embryos. Embryos and gametes. "Who came first" as the old adage would remind us.

While understanding the causes and consequences of mutations and we knew them in classical Mendelian genetics sustains our interests and fosters our hopes for better diagnoses and outcomes in the future, to suggest that the simple-minded one gene-one protein paradigm fits all sizes is (we now know) not working. For just how long did we think of conditions like PCOS owed their causality to a single gene defect?

One thing is clear: reproductive genetics, like other domains in medicine, is witnessing a revolution in technology, concept, and practice that continues to occupy in a substantive way the very core principles associated with contemporary human ARTs. While Rothchild's tome may remind us of the role of chance in specifying our genetic destiny from an evolutionary perspective (it is a great read!), looking back to our vertebrate ancestors as they segued from yolky eggs to the

David F. Albertini

eicjarg@gmail.com

1 Center for Human Reproduction, New York, NY, USA zona pellucida-enclosed cargoes we work with today brings the concept of hatching a bit closer to home.

The real question is why have we practitioners of human ARTs taken hatching to a new level? What forces have driven our laboratory devices-lasers, acid solutions, fine glass knives - to pierce the shell of mammalian embryos that stands at the interface of successful implantation?

One of the very powerful aspects of time-lapse imaging has been the prospective view it provides over the course of embryo culture. Our issue this month builds upon various facets of the biology of human blastocysts, drawing upon not only the insights being gleaned from time-lapse imaging but taking into consideration what breaching the zona pellucida may mean with respect to the embryo's ability to differentiate before or after transfer. The paper from Inoue and colleagues takes us back to the very beginnings of zona manipulation required for performing ICSI, noting that the residual scar ("trace" by their terminology) becomes an active site for cell loss as the embryo not so effortlessly attempts to maintain a quorum of cell density all the while exercising expansion in anticipation of natural hatching [2]. The irony they point out is that in the end, the ICSI scar may compromise the embryo's ability to hatch on its own.

No worries, though! Assisted hatching itself, as well as the need to compromise the integrity of the zona for purposes of biopsying the embryo, has come to be the standard of care in human ARTs with your choice of weaponry being left up to a given center's preference [3]. And along the pathway promoting acceptability for the biopsy of embryos allowing PGT have been claims to condone iatrogenic interventions of this type of less damaging outcomes if inflicted on blastocysts (socalled day 5/6) rather than day 3 embryos contemplating and executing the process of compaction [4]. The question remains, however, as to whether lesioning the zona early or late during culture has an impact either proximally during implantation or down the road when it comes to pregnancy outcomes. Recent scholarship offers a note of optimism from the studies 
of He and collaborators in which neonatal health was monitored following biopsy for PGT [5] but as recognized by Berger, variations in practice from one center to the next make generalizations risky business until longitudinal studies involving multiple centers are performed [6]. Just how perturbing zona lesions will amount to in the long run has yet to be determined. And given the countless healthy births realized through ICSI or PGT, the plasticity and resilience exhibited by human embryos serve only to prompt the question of what impeding natural hatching means as we look ahead to the future.

Reflecting back on Rothchild's comment gives us pause as to the enormous amount of genetic flexibility that science was well aware of 15 years ago and how this dimension of mammalian reproduction has come full circle in the debates over mosaicism, an apparently hominid phenomenon. With the challenge of contextualizing the form, substance, and practice of PGT a matter of utmost importance in the field of human ARTs [7], we sincerely hope that with this issue of JARG our readership will take note of the multiple concerns that the hatching of a new plot in reproductive genetics has ushered in hopefully for the benefit of stakeholders and practitioners alike.

\section{References}

1. Rothchild I. The yolkless egg and the evolution of eutherian viviparity. Biol Reprod. 2003;68(2):337-57.

2. Inoue $\mathrm{T}$, Uemura $\mathrm{M}$, Miyazaki K, Yamashita $\mathrm{Y}$. Failure of complete hatching of ICSI-derived human blastocyst by cell herniation via small slit and insufficient expansion despite ongoing cell proliferation. J Assist Reprod Genet. 2019. https://doi.org/10.1007/s10815-019-01521.

3. Alteri A, Vigano P, Maizar AA, Jovine L, Giacomini E, Rubino P. Revisiting embryo assisted hatching approaches: a systematic review of the current protocols. J Assist Reprod Genet. 2018;35(3):367-91.

4. Scott RT Jr, Upham KM, Forman EJ, Zhao T, Treff NR. Cleavagestage biopsy significantly impairs human embryonic implantation potential while blastocyst biopsy does not: a randomized and paired clinical trial. Fertil Steril. 2013;100(3):624-30.

5. He H, Jing S, Lu CF, Tan YQ, Luo KL, Zhang SP, et al. Neonatal outcomes of live births after blastocyst biopsy in preimplantation genetic testing cycles: a follow-up of 1721 children. Fertil Steril. 2019;112(1):82-8.

6. Berger JJ. Primum non nocere: are we closer to saying that the trophectoderm biopsy does no harm? Fertil Steril. 2019;112(1):35-6.

7. Popovic M, Dheedene A, Christodoulou C, Taelman J, Dhaenens L, Van Nieuwerburgh F, et al. Chromosomal mosaicism in human blastocysts: the ultimate challenge of preimplantation genetic testing? Hum Reprod. 2018;33(7):1342-54.

Publisher's note Springer Nature remains neutral with regard to jurisdictional claims in published maps and institutional affiliations. 